\title{
Measuring Visitors' Observation and Perception on Animal Welfare in National Zoo
}

\author{
Kamal Halili Hassan \\ Faculty of Law, Universiti Kebangsaan Malaysia; Email: k.halili@ukm.edu.my
}

\author{
Doi:10.5901/mjss.2015.v6n6s2p33
}

\begin{abstract}
The promotion of animal welfare has attracted much interest in developing countries including Malaysia. This article examines animal welfare in terms of the appropriate zoo regulations using both qualitative and quantitative research in evaluating its status in Malaysia. For this purpose, a survey was conducted among visitors at the National Zoo in Kuala Lumpur, Malaysia seeking their responses on issues such as animal food/diet, cages/enclosures, the safety of animals, area environment, and visitors' actions. Overall, visitors believed that zoo animal welfare was well managed and catered to by the zoo operator.
\end{abstract}

Keywords: Animal welfare, Zoo operators, Malaysia, National Zoo, Wildlife Conservation Act 2010

\section{Introduction}

Official animal welfare governance in Malaysia began with the enactment of the Animal Act 1953. However, the act was limited in scope as its main aim was to control the spread of diseases to animals and human beings and to ensure that the animals remain healthy. Enforcement under the act was tasked to the Department of Veterinary Services, Ministry of Agriculture and Agro-based Industry. A more comprehensive legislation, the Wildlife Conservation Act 2010, was enacted giving more powers to the Department of Wildlife of the Ministry of Environment to protect animal welfare and prosecute those who abuse animals (Hassan, 2015a).

The concept of animal welfare has developed over many generations (Appleby, 1999; Stafleu et al., 1996). In a nutshell, animal welfare is based on the principle that animals should not be abused, mistreated or abandoned (Broom, 199; Duncan, 1996). To ensure the promotion of animal welfare, governments and organisations institute good practices, and rules and regulations (Duncan, 2002; Fraser et al., 1997). This paper discusses animal welfare in the context of zoo regulations and is based on the Malaysian experience. An empirical study was carried out at the National Zoo in Kuala Lumpur to gauge the standard of animal welfare based on the enacted regulations.

\section{Methodology}

Using mixed qualitative and quantitative methods, the author discusses how animals in the National Zoo are treated based on the governing regulations. The qualitative method is used to discuss and analyse statutes, regulations, caselaw, and public documents for this research (Yaqin, 2007). The quantitative method is based on a survey/questionnaire distributed to 113 visitors at the zoo in January and February 2015. The visitors were asked questions related to zoo management to determine whether animal welfare standards met with the zoo regulations. Responses were then processed using SPSS.

\section{Literature Review on Animal Welfare Regulations}

In the late 1990s the animal rights movement adopted a more rigorous approach by using legislative and judicial processes to achieve their goals (Hewson, 2003). Laws and regulations were enacted to impose responsibilities on humans and corporate bodies such as zoo operators in the treatment of animals (Harrop, 1997; Radford, 2001; Veissier et al., 2008). Animal welfare supports the humane treatment of animals and humans have a responsibility for animal care (Yarrow, 2009). The champions of animal welfare allow that animals can be used for scientific research, food, education, zoos or sanctuaries, and to be kept as pets (Hassan, 2015a; Hosey et al., 2013). Even their use for tourism is not prevented as long as the animals are treated according to good practices or regulations (Hassan, 2015b; KileyWorthington, 1989).

There seems to be conflicting approaches in addressing "animal rights" and "animal welfare" issues. Champions of 
the former are fairly aggressive to the extent that they undermine the more important goal of animal welfare. They argue that animal rights should be accorded the status of property rights where they equate animal with human rights. If such a right is pursued then animals cannot be used for human consumption, something which is actually against the order of nature. Animal rights is a radical ideology based on the assumption that all species in this world are equal (Fraser, 1995).

Fraser et al. (1997) elaborates on the concept of animal welfare by categorizing them into three ethical concerns namely that (1) animals should lead natural lives through the development and use of their natural adaptations and capabilities, (2) animals should feel well by being free from prolonged and intense fear, pain, and other negative states, and by experiencing normal pleasures, and (3) animals should function well, in the sense of satisfactory health, growth and normal functioning of physiological and behavioural systems. All these three concerns actually lead to a common position that animals should be treated well in terms of their behaviour and physiological needs. It is a challenge therefore for these animal needs to be met when animals are kept for human purposes.

The philosophy was somewhat modernized by Singer $(1975 ; 2009)$ who coined the term "speciesism" in reference to the different treatment of existing species. However, Jamison (2004) still maintains the concept of the animal rights movement which is driven by four social conditions: urbanization, anthropomorphism, evolutionary theory, and egalitarianism. Urbanization gives rise to modern living where animals are used for tourism purposes; anthropomorphism refers to the belief that animals need to be treated like humans; the acceptance of the evolutionary theory means that eventually animals have equal status as humans in terms of rights; and egalitarianism is premised on the notion of affinity for equal rights among species.

\section{Zoo Regulations in Malaysia}

Legislation and regulations determine the governance, roles, and obligations of staff managing zoos (Hosey et al., 2013) with the objective of ensuring and maintaining the welfare of animals housed in them (Kleiman et al., 2010). Several legislations have been enacted in Malaysia for that purpose (Yoga, 2012) of which the primary one is the Wildlife Conservation Act, 2010. Several provisions contained in the act cover animal welfare within and outside zoos.

The act has general provisions on the management of zoos with details provided in a related regulation, namely the Wildlife Conservation (Operation of Zoo) Regulations 2012. The act relates to the requirement of permits and licences which enable government agencies to monitor the treatment of animals.

One of the salient features of Act 716 is the requirement for permits and licences for the conservation and keeping of wildlife (Hassan, 2015). Although the act refers to individuals, it also applies to entities or zoo operators as covered by Section 10. Section 10(1) states that no person shall operate a zoo or operate a wildlife exhibition without a permit granted under the act. Further, sub section (2) provides that a special permit is required where the zoo operations or wildlife exhibitions involve any totally protected wildlife. These are the only specific operations regarding zoos in the parent act. Detailed provisions on zoo operations are spelled out in Regulations 2012.

Penalties in the form of imprisonment and fines are provided to enforce the act and regulations. Any person who operates a zoo or wildlife exhibition without a permit is liable to a fine not exceeding RM70,000 or to imprisonment not exceeding 3 years or both (section 66). Further, any person who has totally protected wildlife for his zoo or wildlife exhibition without a permit can be liable to a fine not exceeding RM100,000 or to imprisonment not exceeding 2 years (section72(1)).

Animal cruelty takes many forms and is the antithesis to animal welfare and both the act and its regulations seek to ensure the prevention of ill treatment of animals. It is an offence for any person to commit an act which can be considered as cruelty to animals such as beating, torturing, neglecting to supply sufficient food or water, or keeping wildlife in a manner that causes unnecessary pain or suffering including housing them in premises not conducive to their comfort or health. This is enforced by imposing a fine of not less than RM5,000 and not more than RM50,000 or to imprisonment for a term not exceeding 1 year or both on any such offences.

The regulations derive from the main act and the provisions are detailed in nature. Offences can be punished by courts either under the act or regulation or both. The main purpose of the Wildlife Conservation (Operation of Zoo) Regulations 2012 is to ensure the welfare of the animals or wildlife kept in zoos (Hassan, 2015) in regard to matters such as enclosures, cages, food, upkeep, health, etc of the wildlife. Under the 2012 regulations, a zoo operator means any individual, statutory body, company, association, or local authority owning or operating a zoo while zoo refers to any area or premise which keeps or places 50 species or 100 more wildlife whether for conservation, education, research, or recreational purposes, and is open to the public.

The 2012 regulations repeat the provisions of the parent act which requires a permit for zoo operations. Enclosures or cages are an important aspect in ensuring animal welfare in zoos and the regulations state explicitly that their design 
must be appropriate to the natural behavior and basic needs of the wildlife. In fact, the design of the enclosure must first be submitted to the Director-General for approval. The schedule to the regulations provides the specifications for the enclosure such as the category of species it will house and its size and height. For reptilia and amphibians such as crocodiles and snakes, an additional condition is to provide a watery enclosure.

The Animal Act 1953 (Act 76) was already in force before the enactment of Wildlife Protection Act 2010. The 1953 Act however does not deal specifically with animal welfare protection in zoos. The Act is more for preventing and controlling the spreading of diseases of animals, the movement of animals and preventing the cruelty to animals, among others. The ultimate aim of the Act is not only to ensure the spreading of diseases to animals but also to human beings. Unlike the 2010 Act which empowers the Ministry of Environment to be in charge of the Act, the public authority in charge of the enforcement of the 1953 Act is the Department of Veterinary, Ministry of Agriculture and Agro-based Industry. Part II of the 1953 Act deals with the importation and exportation of animals and birds. No person is allowed to import or export animals to and from Peninsular Malaysia. Powers are given to the authority to examine any animal upon its arrival. It is also the duty of the master of any ship or aircraft to report the arrival or intended arrival of animals to the relevant authority.

In discharging his duty the veterinary officer is empowered with discretionary power to either refuse permit or order the infected animals to be destroyed or detained in quarantine. The 1953 Act not only provides for examination of animals at the point of entry into the country but also at any given time. If the veterinary officer has reason to believe that any animal may be infected with disease he may subject such animal to an examination. As a consequence of such examination, the officer may order the immediate isolation or destruction of any infected animal. No compensation shall be payable for animal destroyed by the authority.

The 1953 Act (Part IV) also does provide for the protection against cruelty to animals. Powers are given to the veterinary officer, Police officer and the local authority to take action against any person or body that cause cruelty to animals. The acts of cruelty to animals in this context include beating, kicking, torturing, overriding, overloading, torturing, terrifying, ill treating and not maintaining confined animals properly. The penalty, upon conviction, is a fine not exceeding RM200 or imprisonment not exceeding 6 month or both. The monetary fine is considerably low. However, in the case of captivating or keeping animals in enclosures or closed premises such as zoos the Act has no special provision. For that purpose, we have to refer to other legislation (Wildlife Protection Act 2010 and its zoo regulations) that provides for better treatment and management of captivated or confined animals.

\section{Empirical Study: Methods and Materials}

The questionnaire covered 45 questions relating to the observation and perception of visitors to the zoo. Part $A$ is on the demographic of the respondents. Part B comprised 10 questions covering animal food and diet to determine whether the animals are provided a proper diet and clean water and is based on the observations and perception of visitors and not on any scientific test. The questions are whether: (1) the food for the animals contain adequate nutrients; (2) the food is not contaminated; (3) the food is of sufficient quantity; (4) the food zoo is of sufficient quality; (5) the food is in accordance with the natural diet of the animals; (6) supply of clean drinking water is available at all times; (7) the supply of clean drinking water is adequate; (8) the food containers are placed in a suitable location; (9) the drink containers are placed in appropriate locations; (10) the food containers are clean, and (10) the food waste is organized properly.

Part $C$ questions relate to the animal enclosures and whether they are appropriate. The questions are: (1) The cages housing the animals are comfortable; (2) Each animal housed in a cage is in accordance with the natural habitats of animals; (3) The animal cages have adequate lighting; (4) The animal cages have proper ventilation; (5) The animal cages are kept clean; (6) The animal cages are managed well so that they will always be safe for the animal species; (7) The cages are free from dangerous animals; (8) The size of the enclosure is suitable for the caged animals; (9)The animals have enough room to move; (8) The design of the cages for several animals is consistent with the pattern of the animal behavior; (9) The floors confinement of animals are in accordance with the nature of the animals; (10) The design of the fence is approriate to prevent animals from escaping; (11) Each enclosure has natural amenities such as bedding, tree branches, holes and hanging places, and (12) Each cage has a shelter or refuge areas for animals to withdraw.

Part D of the questionnaire relates to (1) The sturdiness of the animal cages; (2) whether the distance or barriers between the animals in a cage and visitors are appropriate for the safety of both; (3) whether the distance or barriers between the animals in a cage and visitors are appropriate to prevent direct contact between them, and (4) whether the cage structures allow draining of excess water (such as making slope, pipe kits and interlocking). The purpose of these questions is to ascertain the welfare and safety of the animals in cages.

Part E centres on the overall zoo environment. Questions posed are whether: (1) the layout and landscaping of the 
zoo are appropriate to the animal species; (2) the animal exhibit area is clean; (3) management is constantly monitoring the animal waste and rubbish in the zoo; and (4) drainage systems such as ditches and drains are well maintained.

Part F pertains to visitors to the zoo. Questions asked are whether: (1) visitors are allowed to feed some animals; (2) visitors are allowed to have contact with animals; (3) the zoo staff always monitor the safety of animals; (4) all animals that can endanger visitors are always kept in cages; (5) the zoo staff always takes care of the animals' welfare; (6) animal training does not cause stress and anxiety to them; and (7) animal shows are in accordance with the natural habits of the animals.

The questionaire uses Likert Scale which is as follows:

1 - Not very satisfactory

2 - Not satisfactory

3 - Less satisfactory

4 - Satisfactory

5 - Very Satisfactory

T - Total

$\mathrm{M} / \mathrm{A}=$ Means/Average

S.D. = Standard Deviation

\section{Results and Discussion}

This study sought to evaluate the observations and perceptions of visitors on various aspects of animal welfare at the National Zoo in Kuala Lumpur, Malaysia through a survey conducted in January and February 2015 that covered 113 visitors to the zoo. The respondents comprised the following table 1 :

Table 1: (Respondents' Demographic)

$\begin{array}{ccc}\text { Age } & \text { Frequency } & \text { Percentage } \\ 10-20 \text { years } & 8 & 6.7 \\ 21-30 \text { years } & 85 & 70.8 \\ 31 \text { - } 40 \text { years } & 19 & 15.8 \\ \text { Over 40 years } & 8 & 6.7 \\ \text { Sex } & & \\ \text { Male } & 106 & 88.3 \\ \text { Female } & 7 & 5.8 \\ \text { Race } & & \\ \text { Malay } & 106 & 88.3 \\ \text { Chinese } & 7 & 5.8 \\ \text { Indian } & 4 & 4.2 \\ \text { Others (Bisaya \&Bumiputera) } & 2 & 1.7 \\ \text { Religion } & & \\ \text { Islam } & & \\ \text { Buddha } & 109 & 90.8 \\ \text { Hindu } & 5 & 4.2 \\ \text { Christian } & 4 & 3.3 \\ \text { Marital status } & 2 & 1.7 \\ \text { Single } & & \\ \text { Married } & 83 & 69.2 \\ & 37 & 30.8\end{array}$

Although the demographics of the respondents in table 1 (Part A) are not representative of the population in Malaysia, for the purposes of the study it is acceptable as perceptions on animal welfare generally transcend sex, race or religion. 
Table 2: Part B: Animal Food/Diet

\author{
No Items \\ 1 Animal food in this zoo contains adequate nutrients \\ 2 Food in this zoo is not contaminated \\ 3 Animal food in this zoo is given in sufficient quantities \\ 4 Animals food in this zoo are in accordance with the natural diet of the animals \\ 5 Supply of clean drinking water is available at all times \\ 6 Supply of clean drinking water is adequate \\ 7 Food containers are placed in a suitable location \\ 8 Drink containers are placed in appropriate locations \\ 9 Food containers are clean \\ 10 Food waste in this zoo is organized properly
}

$\begin{array}{cccccccc}\text { M/A } & \text { S.D. } & \mathbf{1} & \mathbf{2} & \mathbf{3} & \mathbf{4} & \mathbf{5} & \mathbf{T} \\ 3.92 & 0.67 & - & 3 & 23 & 75 & 19 & 120 \\ 3.83 & 0.76 & 1 & 6 & 23 & 75 & 17 & 120 \\ 3.87 & 0.71 & - & 5 & 24 & 73 & 18 & 120 \\ 3.91 & 0.67 & - & 2 & 27 & 71 & 20 & 120 \\ 3.87 & 0.76 & - & 5 & 28 & 65 & 22 & 120 \\ 3.94 & 0.73 & - & 4 & 23 & 65 & 22 & 120 \\ 3.93 & 0.71 & - & 5 & 20 & 74 & 21 & 120 \\ 3.97 & 0.69 & - & 4 & 18 & 76 & 22 & 120 \\ 3.72 & 0.80 & - & 10 & 30 & 64 & 16 & 120 \\ 3.78 & 0.80 & -10 & 25 & 67 & 18 & 120\end{array}$

M/A S.D. $12 \begin{array}{lllll}2 & 3 & 4 & 5 & \mathrm{~T}\end{array}$

$\begin{array}{llllllllll}3.83 & 0.76 & 1 & 6 & 23 & 75 & 17 & 120\end{array}$

$3.870 .71-5247318120$

$27 \begin{array}{lll}20 & 120\end{array}$

-

$3.930 .71-5207421120$

$3.720 .80-10306416120$

$3.780 .80-10256718120$

Table 2 shows the result on animal food, including its cleanliness, or diet is important to the welfare of animals in zoos as it ensures their good health. Favourable responses were received on all questions relating to this with all responses in the range of 1-5 scored above 3 points on average showing satisfactory and good responses. The highest score in the above survey was on the position of drink containers placed in the zoo which stood at 3.97 whilst the lowest score (3.72) was on the cleanliness of the food containers. The second highest score was on the question of placement of food containers where the average (min) was 3.93.

Table 3: Part C: Cages/Enclosure

\section{Noltems}

1 The cages housing the animals are comfortable

2 Each animal housed in cage is in accordance with the natural habitats of animals

3 The animal cages have adequate lighting

4 The anima' cages have proper ventilation

5 The animal cage are kept clean

6 The animal cages are managed well so that they will always be safe for the animal species

7 The caged animals are free from dangerous animals

8 The size of the enclosure is suitable for the caged animals

9 The animals have enough room to move

10 The design of cage occupied by several animals is consistent with the pattern of the animal behaviour

11 The floor confinement of animals are in accordance with the nature of the animals were placed

12 The design of fence is appropriate to prevent animals escaping

13 Each enclosure has a natural amenities such as bedding, tree branches, holes and hanging places

14 Each cage has a shelter or refuge areas for animals to withdraw
M/A S.D. $12345 \quad T$

$3.840 .72-5277018120$

$3.780 .74-8247414120$

$3.940 .70-4217322120$

$4.010 .61-1197822120$

$3.780 .73-6306915120$

$3.970 .72-5187324120$

$4.000 .74-5186928120$

$3.880 .71-7177917120$

$3.880 .74-6227220120$

3.93 0.581218315120

3.820.69815218112120

$4.030 .63-2167923120$

4.080 .6411118225120

$4.080 .63-2137827120$

Table 3 demonstrates the result on cages or enclosures requirements form an important part of zoo regulations in Malaysia. Accordingly, many questions on this aspect were posed to respondents. Most respondents were satisfied with the standard of cages or enclosures. The highest score (4.08) was obtained for two questions on (i) natural amnesties in the enclosure and (ii) the availability of shelter or refuge areas in the cage, while the lowest score (3.78) was on the cleanliness of the cages. The second highest score was 4.03 on the question on the design of the cages and whether they are able to prevent animal escapes. This shows that the respondents considered safety an important factor in zoos.

Table 4: Part D: Safety Of Animal In Captivity

\section{Noltems}

1 The animal cages are built with sturdy construction to confine animals

2 The distance or barriers between the animals in a cage and visitors are appropriate for the safety of

2 visitors and animals.

3 The distance or barriers between the animals in a cage and visitors are appropriate to prevent direct contact between animals and visitors

M/A S.D.12345 T

4.020 .7622157427120

4.100 .6911147331120

4.150 .7212117036120

4 The structures of cage allow draining of excess water (such as making slope, pipe kits and interlocking) 4.020 .6711147331120

Table 4 demonstrates the result on the safety of the animals in the zoo is also important especially in regard to the 
structures and their distance from visitors. The respondents gave very positive feedback on all questions posed in this area with scores exceeding 4.00. The highest score of 4.15 was on the appropriateness of the distance between the cages and visitors with many agreeing that the existing distance is appropriate.

Table 5: Part E: Area Environment

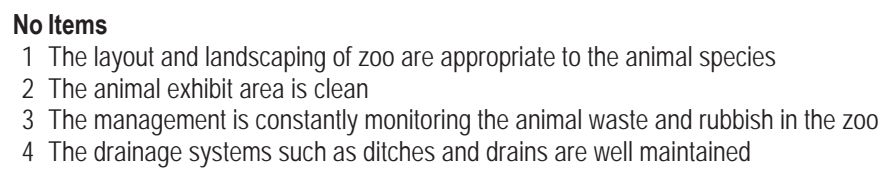

1 The layout and landscaping of zoo are appropriate to the animal species

2 The animal exhibit area is clean

3 The management is constantly monitoring the animal waste and rubbish in the zoo

4 The drainage systems such as ditches and drains are well maintained

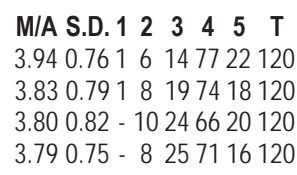

Table 5 shows the result on the area environment or surrounding is important in determining animal welfare in zoos. The layout, landscaping and other systems have to be appropriate in terms of the animals' needs and behaviour. For this part, the scores obtained were fairly good, with the highest score at 3.94, that is, the layout and landscaping of zoo which are appropriate to the animals.

Table 6: Part F: Visitors

\author{
No Items \\ 1 The visitors are not allowed to feed some animals \\ 2 The visitors are not allowed to have contact with animals \\ 3 The zoo's staff always monitor the safety of animals \\ 4 All animals that can endanger visitors are always kept in cages \\ 5 The zoo's staff always take care of the animals' welfare \\ 6 The training given to the animals do not cause stress and anxiety to animals \\ 7 Animal show is in accordance with the natural habits of the animals
}

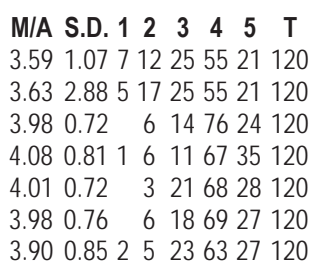

Table 6 demonstrates the result on the role of the visitors to the zoo is important in determining animal welfare. For example, providing animals with unsuitable food can endanger them. The overall score in this category is good with the highest point (4.08) obtained relating to the keeping of dangerous animals in cages, suggesting that visitors are very mindful of their safety. The second highest score, at 4.01, was on the care of the animals by the keepers. Visitors are not allowed to touch (median score 3.63) or feed the animals (3.59) as the food or substances might not be suitable to them. These are zoo regulations that ensure animal welfare in terms of contact with visitors.

Animals in zoos are also occasionally used in shows and for that purpose they are trained by the zoo operators. The regulations provide that such training must not have any element of cruel treatment and that the shows must accommodate the natural habitat of the animals. Responses on these issues were favourable with scores of 3.98 and 3.90 respectively.

\section{Conclusion}

The Wildlife Conservation Act 2010 and its regulations on the operations of zoo is a significant milestone for the animal welfare movement in Malaysia. Compared to the preceding legislation, i.e the Animal Act 1953 (as discussed above), the 2010 Act and its regulations in particular are comprehensive enough to cover all aspects of animal protection from diet, enclosures, and animal shows. At least from the theoretical aspect, the regulations are complete guidelines on which zoo operators can rely on. It only requires sound implementation by all parties concerned to ensure the provisions are adhered to. The survey undertaken above gauged the implementation of the regulations by taking the National Zoo as a sample study. Overall, the results of the survey show that, based on the observations and perceptions of visitors, the zoo has discharged its duty satisfactorily in taking care of the animals housed in its premises.

\section{Acknowledgements}

The author would like to record his appreciation to Sumitomo Foundation, Japan for providing this research grant (20142015). 


\section{References}

Appleby, M.C., (1999) What Should We Do About Animal Welfare? 1st Edn., Oxford: Blackwell Science.

Broom, D.M., (1991) Animal welfare: Concepts and measurements. Journal of Animal Science, 69: 4167- 4175.

Duncan, I.J.H., (1996) Animal welfare defined in terms of feelings. FAO, Ontario: Guelph University.

Duncan, I.J.H., (2002) Poultry welfare: Science or subjectivity? Brit. Poultry Sci., 43: 643-652.

Fraser D, Weary DM, Pajor EA and Milligan BN., (1997) A scientific conception of animal welfare that reflects ethical concerns, Animal Welfare 6: 187-205.

Fraser, D., (1995) Science, values and animal welfare: Exploring the 'Inextricable Connection'. Animal Welfare, 4: 103-117.

Gareth, D. (2006) Visitors' behaviour in zoos: A review. Anthrozoos, 19(2): 143-157.

Hassan, KH., (2015a) Application of the wildlife conservation 2010 (act 716): the Malaysian experience, American Journal of Animal and Veterinary Sciences, 10(1): 43-46.

Hassan, $\mathrm{KH} .,(2015 b)$ tourism and wildlife legislation: welfare issues of animals in zoos and national parks, Proceedings of the International Conference on Natural Resource, Tourism and Service Management, 14 - 16 April 2015. 177-182.

Harrop, SR., (1997) Dynamics of wild animal welfare law. Journal of Environmental law, 9: 287-302.

Hewson, C.J., 2(003) What is animal welfare? Common definitions and their practical consequences. Can. Vet. J., 44: 496-499.

Hosey, G., V. Melfi and S. Pankhurst, (2013) Zoo Animals: Behaviour, Management and Welfare, Oxford: Oxford University Press.

Jamison, W. (2004) The animal rights struggle. Journal of the American Veterinary Association.

Kiley-Worthington, M., (1989) Ecological, ethological and ethically sound environments for animals: Toward symbiosis. J. Agric. Ethics, 2: $323-247$.

Kleiman, D.G., K.V. Thompson and C.K. Baer, (2010) Wild Mammals in Captivity: Principles and Techniques for Zoo Management, 1st Edn., Chicago: University of Chicago Press.

Radford, M., (2001) Animal welfare law in Britain: regulation and responsibility, UK: Cab Direct.

Rollin, B.E., (2006) Animal Rights and Human Morality. 3rd Edn., New York: Prometheus Books.

Singer, P (1975) Animal liberation, USA: Random House.

Singer, P. (2009) Animal liberation: A new ethics for our treatment of animals, New York: Harper.

Stafleu, FR., Grommer, FJ, Vorstenbosch., (1996) Animal welfare: evolution and concept, Animal Welfare, 5(3): 225-234.

Veissier I, Butterworth A, Bock B, Roe E., (2008) European approaches to ensure good animal welfare, Applied Animal Behaviour Science, 113(4): 279-297.

Yarrow, Greg (2009) Wildlife and wildlife management, Clemson Extension, Fact Sheet 36, May.

Yaqin, A., (2007) Legal Research and Writing. Kuala Lumpur: LexisNexis.

Yoga, S.S., (2012) New regulation seeks to improve zoo conditions, The Star Online. http://www.thestar.com.my/Lifestyle/Features/ 2012/04/24/New-regulation-seeks-to-improve-zoo-conditions/ 